\title{
Incorporating Virtual Reality Technology in Safety Training Solution for Construction Site of Urban Cities
}

\author{
Zheng $\mathrm{Xu}$ (D) and Nan Zheng * \\ Faculty of Civil Engineering, Monash University, Clayton, VIC 3800, Australia; Zheng.Xu2@monash.edu \\ * Correspondence: Nan.Zheng@monash.edu
}

Citation: Xu, Z.; Zheng, N. Incorporating Virtual Reality Technology in Safety Training Solution for Construction Site of Urban Cities. Sustainability 2021, 13, 243. https://doi.org/10.3390/su 13010243

Received: 23 November 2020 Accepted: 24 December 2020 Published: 29 December 2020

Publisher's Note: MDPI stays neutral with regard to jurisdictional clai$\mathrm{ms}$ in published maps and institutional affiliations.

Copyright: (C) 2020 by the authors. Licensee MDPI, Basel, Switzerland. This article is an open access article distributed under the terms and conditions of the Creative Commons Attribution (CC BY) license (https:// creativecommons.org/licenses/by/ $4.0 /)$.

\begin{abstract}
The lack of experiential training has become the primary cause of incidents that could have been easily avoided in construction areas, and the implementation of experimental training is crucial in minimizing incidents at construction sites. The limitation on the available training tools has made it impossible to build up a real test site or reproduce the constructing scenarios. This research aims to develop an immersive and interactive multiplayer-based training platform that incorporates virtual reality (VR) technology to improve the safety awareness of workers. The developed simulation platform serves as a training solution, enabling the provision of repeatable and flexible procedures within a secure environment. An evaluation survey was conducted to make a comparison between traditional training methods and the proposed VR solution. Promisingly, the results indicate that workers were better trained under the developed immersive environment, and they could memorize critical points more effectively because the implementation of VR technology can allow people to experience hazardous situations without being physically injured, thus creating a safer and more efficient training environment. This study reveals that the nomination of the proposed VR platform could reap many benefits and become an advantageous tool for construction training, as well as stimulate human-machine interaction research.
\end{abstract}

Keywords: virtual reality; safety training; hazard perception; construction accidents

\section{Introduction}

Generally, the construction sector involves significant safety risks for workers, including fatality risk, due to many factors. There were 183 fatalities (1.4 per 100,000 workers) in Australia in 2019, and the majority were caused by vehicle collision, which accounted for $43 \%$ of total injuries and fatalities [1]. Being hit by moving objects and trapped by moving machinery were the second most severe incident (11\%), in which misconducts by the workers and machinery operators were mostly involved [2]. In such a high-accident environment, every new entrant, unaware of the possible on-site and during-work hazards, is exposed to high health and accident risk. There is a critical need to train the workers safety awareness to ensure a safe working environment for every other construction worker, as well as the smooth operation of construction works.

Human error has been regarded as the principal cause of many injuries in the engineering community [3]. Many unfortunate cases from the past illustrate that workers could easily get injured due to lack of concentration, resulting in falling from a height, being hit by falling objects, being hit by moving machinery, or hitting someone while operating machinery [4]. Lack of safety awareness likely leads to manifest failure on construction sites. Though some construction sites keep anonymous on-site safety records for workers that offer some insights on safety issues, it might not be applicable to other sites and the safety logbooks themselves do not offer any direct or proactive effect on workers' consciousness [5]. Over the years, it is recognized that training should play an important role, and different training solution ideas have been developed and implemented. Based on a thorough review of the emerging technologies for training solutions, researchers [6] state 
that engaging learning experiences are fundamental, and it would be best supported by adopting simulation technologies and abandoning passive means of teaching.

Most practical training programs in a live construction are oral instruction associated with some video instruction [4,5]. As suggested by the name of this type of training, the trainees are orally told what to do and what not to do in a site, generally without observing or experiencing an incident [5]. Feedback from industry professionals suggested that the effectiveness of training depends on the guidance of the training programs, and good trainings should encourage workers to make safety-conscious decisions [7]. Clearly, the introduction of modern information technologies facilitates efficient training. The 360-degree video training is one example method, which involves a 360-degree video of a site delivered through a Head Mounted Display (HMD) with sound effects explaining potential hazards [8]. While these methods improve the training experiences to some extent, the remaining challenge is to instill hazard-recognition skills into new entrants' minds, as the fundamental goal is to maintain a long-term safety awareness which many of the conventional programs are unable to achieve. A study [4] highlighted that low engagement during safety training had been proven to be the main reason for low efficiency in safety-related knowledge inculcation. Given that safety recognition is based on people's subliminal perception of the current situation, theoretically, workers possibly even learn more by just conducting or observing some poor safety performance in construction projects, rather than studying the instructions $[3,4,7]$. This means that providing the opportunities for the workers to face challenges in practice can significantly affect workers hazard identification and produce different training results as compared to conventional methods [9].

Experimental data from several current studies indicate that workers can learn more when required to participate in interactive problem-solving and decision-making [7,9-11]. Regarding hazard recognition and risk perception in construction sites, previous research concluded that participants identified more hazards correctly when they were involved in practical learning [7]. Similarly, the impact of getting involved in practical training on workers' hazard recognition performance was evaluated, and robust statistical significance was found between the engagement, hazard recognition, and risk perception [9]. The effectiveness of information absorption has been proven higher in interactive training than traditional video-based training. Studies also illustrated that people tend to make the correct decision under urgent circumstances $[10,11]$. With the recent rapid development in computer science, virtual reality (VR) technology as a key interactive tool is becoming mature and is applied to facilitate different domains in the engineering world. The immersive experience provided by VR allows people to interact with various virtual objects under different circumstances, and VR technology has been proven to be particularly useful for educational and training purposes [12-17]. For example, a trench safety direction was designed for students to experience fall, struck-by, and caught-in hazards [12]; a collaborative game was created for tower crane operating instruction and safety education [13]; a training system was created for testing trainees' attention and concentration while conducting concrete works in a severe environment [14]; a serious gaming environment was built for students to understand safety material, rules, stipulations delivered on a smartphone [15]; a serious game was created using immersive virtual reality to analyze earthquake behavioral responses and post-earthquake evacuation preparedness [16]; and an exquisitely designed integrated VR simulation platform was used for road crash avoidance that relates to freeway merging [17]. Most of these studies highlighted human-machine interaction instead of mutual influences between users, which contributed to a common limitation of single-player involvement [12,14-17]. Furthermore, VR training applications have been utilized in other scientific fields, such as for medical surgery [18,19], manufacturing [20], and military operations [21]. The simulation research that utilized VR technology has made valuable exploratory efforts; however, many of these studies were carried out using desktop-based computers or smartphones with only limited degree of immersion. Some studies relied on HMD-supported systems that were only focused on simple tasks, 
such as a single grab or a click for interactions; others were only presented with a simple scenario, such as a fixed route for certain training due to the limitation of the hardware capabilities such as graphics card support.

Motivated by existing studies, the objective of this work is further exploring the potentials of a VR-based training system for safety training at construction sites. To this end, a multi-level VR training system that allows mutual interaction between users was developed with the assistance of a powerful gaming engine, Unity3D. The training environment provides diverse scenes to familiarize trainees with different safety situations involved in such a construction area. It was designed as an open world for the trainees to move as if they were at construction sites and requires them to identify potential hazards to survive at the end. The proposed solution was compared with one of the classic conventional training methods: a handbook and video presentation. Ten workers who are currently working in a real-world construction site at Pakenham Station, Melbourne, were engaged in experiments to evaluate the authenticity of the proposed environment and validate the performance of the proposed solution.

\section{Methods}

The goal of VR-enhanced training is to create realistic workplace experiences and allow employees to learn from taking risks while working in demanding environments. In this section, we present the methodology for creating, testing, and validating a VR-based training platform for construction sites. To make the descriptions in context, we utilize a railway station construction scenario as an example; nevertheless, the general methodology can be converted with site-specific adjustment for different projects. The chosen construction area was close to the railway since this type of construction site contains various potential hazards due to its complex nature [22], and according to the empirical statistics, fatal incidents are most likely to happen at these sites than others [2]. A set of site components are considered in the platform: Machinery, typical machines such as a tower crane, excavators, loaders; Vehicles, typical transportation modes on-site such as vans and trains that operate on a given schedule generating the health-affecting level of noises.

This VR training platform's development consists of three main parts, namely a threedimensional (3D) modelling stage, the VR environment rendering process, and the training system program design. 3Ds Max and Unity3D were utilized for the system build-up and sounds from the real world were gathered to create the virtual environment. Regarding the hardware, Oculus Quest was selected because of its portability and 3D processing performance [23]. Figure 1 demonstrates the platform architecture.

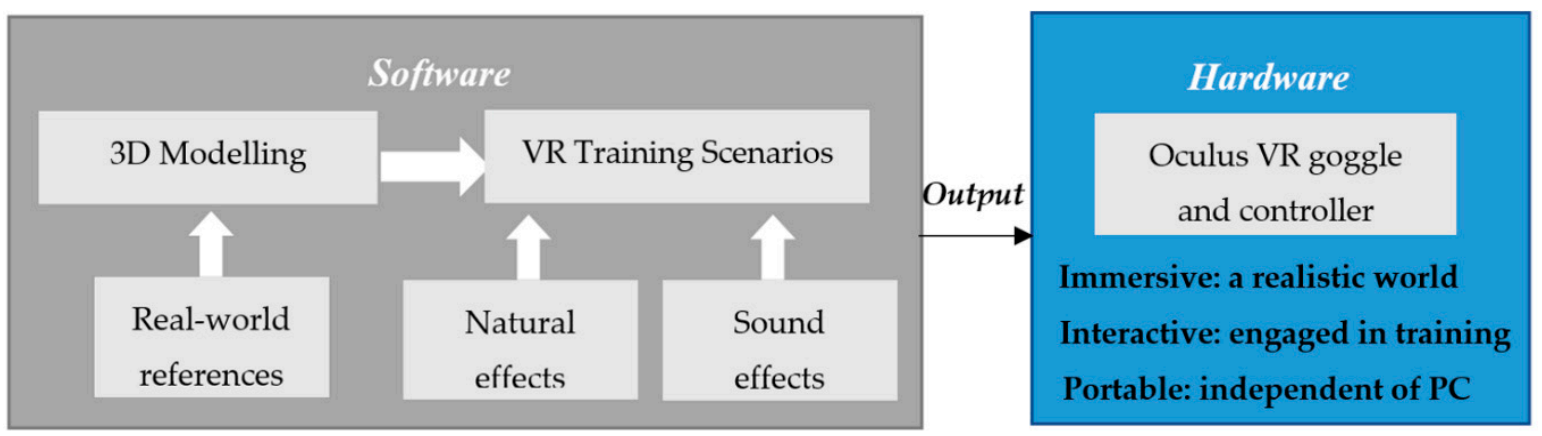

Figure 1. The platform architecture.

In addition, the arrangement of 3D objects in the virtual environment follows the Global Mandatory Requirements for safety and environment (GMRs) that complies with WHS standards [24]. For example, warning signs in terms of mobile plant and vehicles, excavation, and trenching, lifting operations, and electrical safety were properly arranged. The designated pedestrian routes, the specific pathways for general movements of workers, and the separation of vehicles and pedestrian entry points were also included to ensure 
the recreated construction site is logical and reasonable. A programmed security inspector would work to prevent trainees from exposure to hazardous sources in some particular scenarios. The design of this training solution has strictly complied with the WHS requirements related to traffic, plants, and people in the construction environment.

\subsection{D Modelling}

The 3D objects are critical elements in VR environment development, and the quality of those 3D elements can significantly affect the user's subliminal perception regarding the VR open world [25]. The objects in this project were created with properties similar to the real ones and laid a solid foundation for the VR scenario build-up. Objects that are highly involved in construction safety such as personal protective equipment (PPE), machinery (excavator, loader, shovel car, etc.), and safety signs were modelled in detail to impress trainees more and highlight the construction safety awareness logically. Figure 2 gives comparisons of real objects with their models.

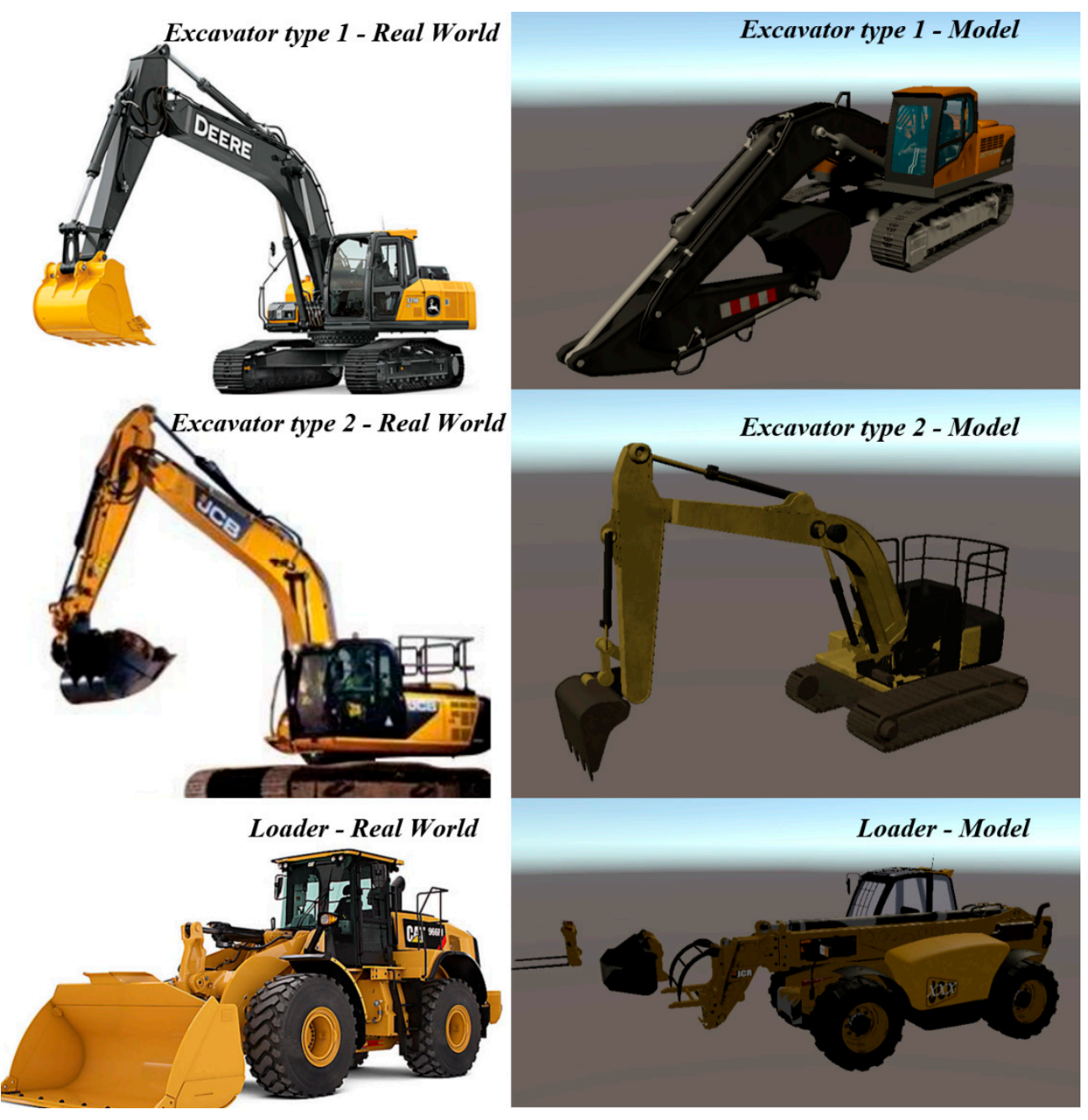

Figure 2. Illustrations of converting real objects into 3D models (created utilizing 3Ds MAX).

Furthermore, essential construction site elements such as workers, crane, warehouse, vehicles, and safety signs were prepared into 3D objects using 3Ds Max as well (see illustrated in Figure 3). These models were segregated as static and dynamic objects to create a relatively realistic virtual world that provides a decent visualization. The model quality depends on the intricacy of the modelling work; however, models in this work have different purposes, so not every single one needs to be exquisite. 


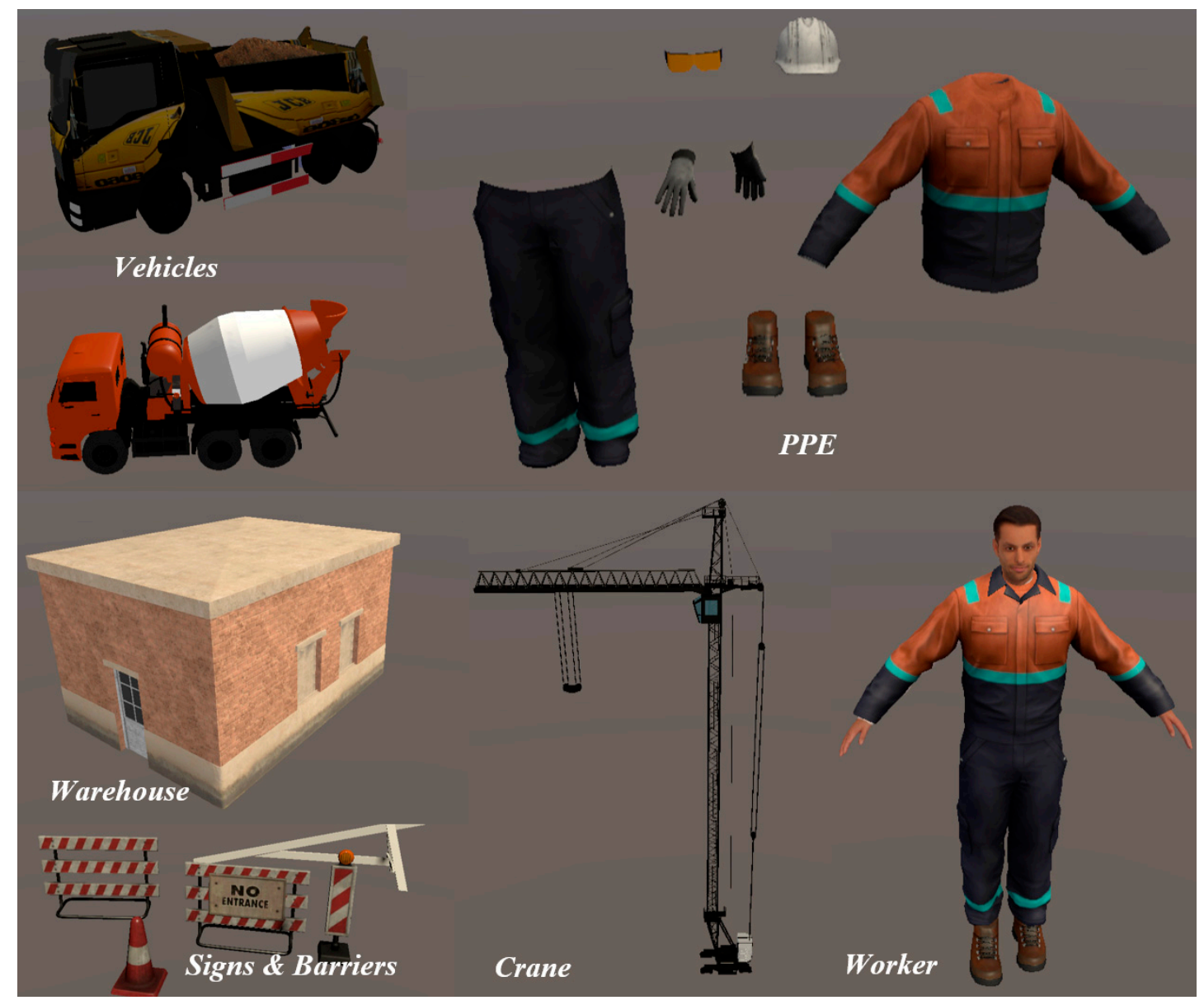

Figure 3. Typical 3D objects used in this project (Refer to general features in construction areas).

\subsection{Simulation Platform}

The proposed training platform contains two core modes: single-player modes and multiplayer modes. Both modes offer two types of scenarios. Each trainee will have to finish four scenes. The training will start at a user-interface (UI), and trainees will be presented the first scene straightforwardly with easy passing conditions (as a warm-up), then a relatively harder scene with increased complexity with respect to the presence of the types of machinery and rougher ground condition, followed by a multiplayer scene associated with more tricky (e.g., hidden) safety hazards, and lastly the most challenging multiplayer scene with simultaneously-operated machinery.

The VR environment was established within Unity3D. This powerful game engine was not only in charge of the rendering process for the 3D objects, but was capable of simulating some real-world effects such as directional light, weather shifting, shadow and shade effects, etc. Besides, the environmental elements such as the ground, plants, and the skybox were generated in Unity3D with assistance of terrain and lighting functions. All the $3 \mathrm{D}$ elements were packaged and integrated on a single Unity project under the control of a series of scripts that handle the properties, functions, and restrictions among objects, so that high-level interactions could be achievable. Figure 4 illustrates the procedure of platform development. 

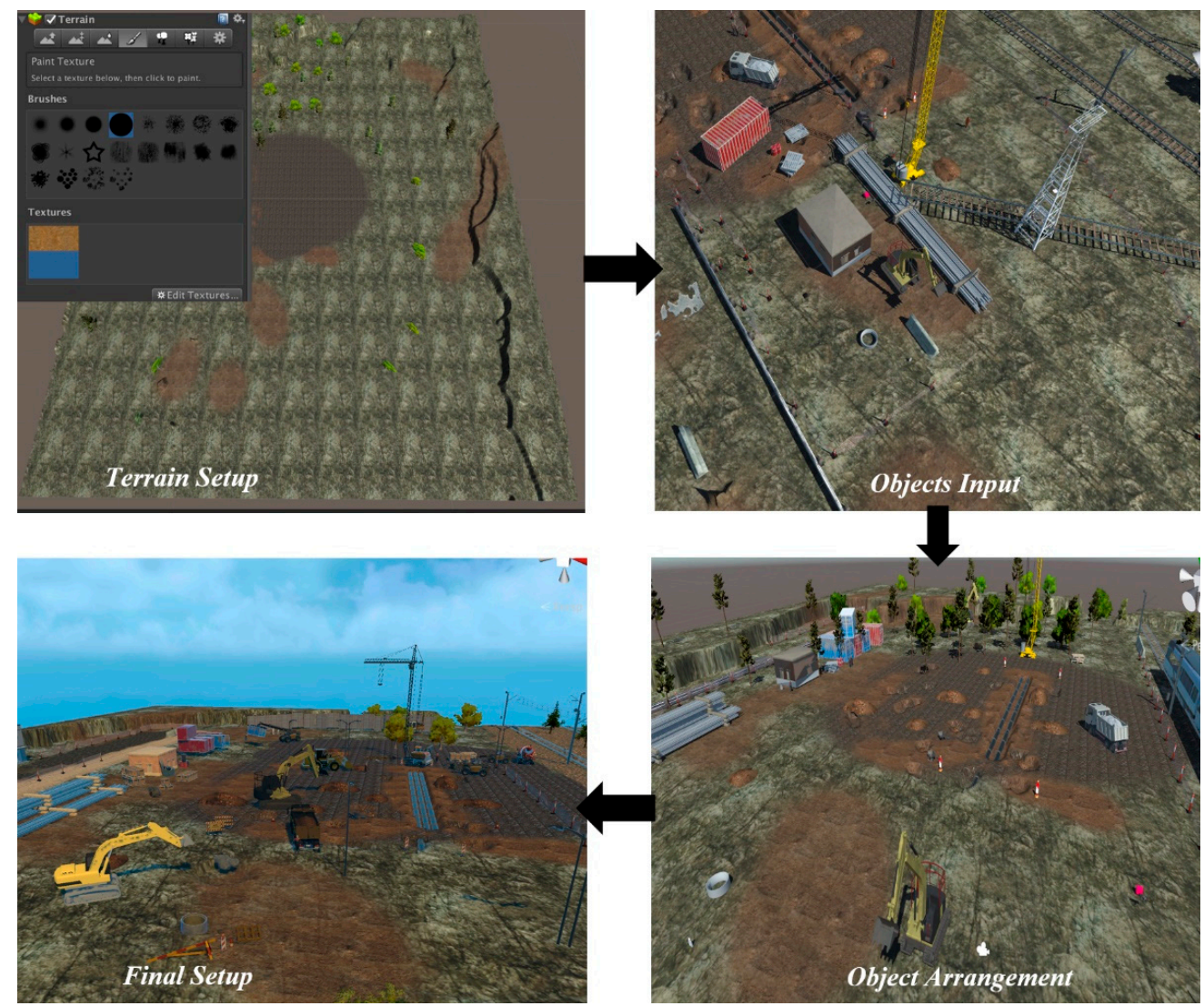

Figure 4. Procedure of platform development (arrows indicating the setup order).

The user interface (UI) was introduced at the beginning of the training session to remind the trainee to put on the PPE. At this scene, all of the PPE functions would be mentioned, and the controller use instruction would also be played through the audio. Figure 5 shows the UI scene of the training program, as well as the supported devicesOculus VR headset and controllers.
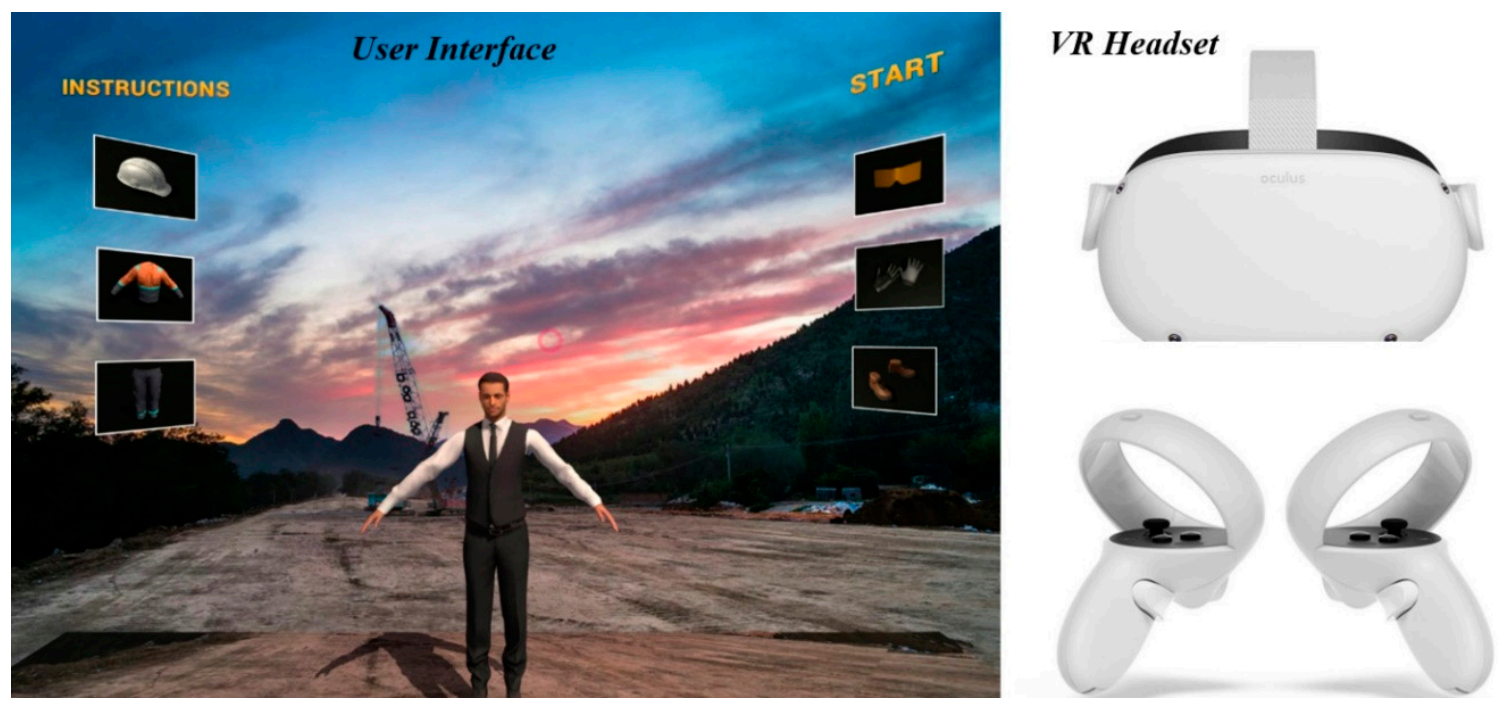

Figure 5. An illustration of the UI and the headset \& controllers for trainees.

The valuable feature of scene switching by Unity provides an opportunity for designing a progressive multi-level training platform. As for the concerned example, we set up four different levels corresponding with proposed scenes with continuously increased 
"difficulties" to train and test the trainees. The goal is for trainees to pass through the levels of tasks without getting into accidents. The same scenario would reload again until the users recognize the issues and avoid any accidents successfully. Table 1 demonstrates the descriptions of each level.

Table 1. The descriptions of each level.
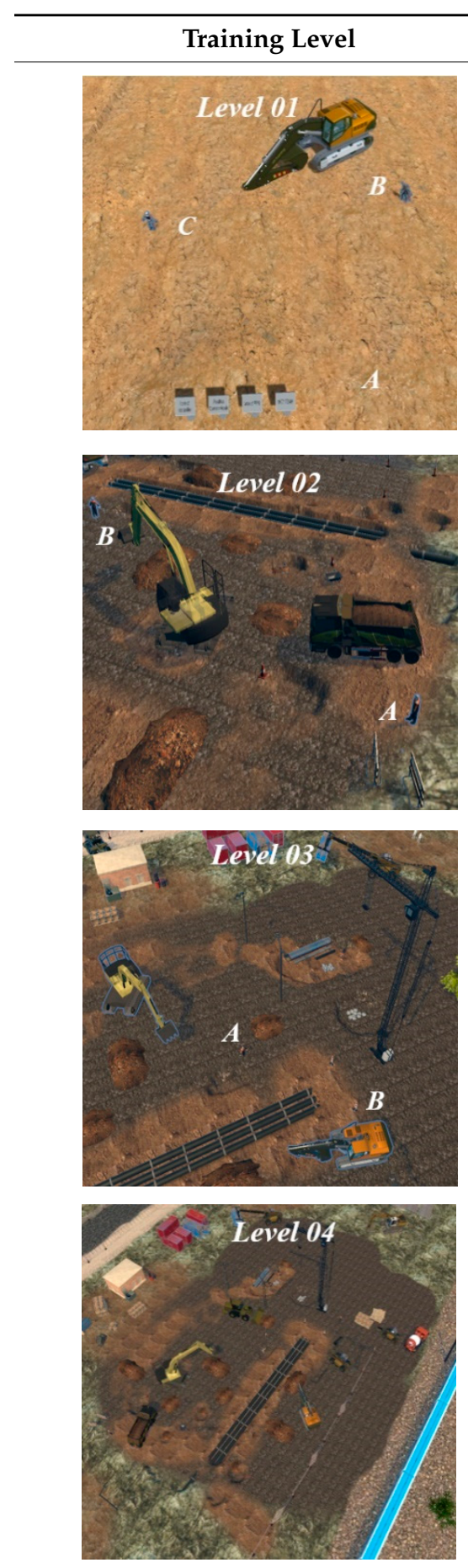

Relatively smooth ground. It contains only single running machinery, which is used for players to get familiar with the VR environment. The player must inform the machinery operator correctly to pass this level. This is the simplest level.

A few gaps on the ground. An excavator and a truck are running simultaneously, and the player has to make sure not to walk on the vehicles' moving track or inform the operators to pass this level. Few objects are arranged at this level.

Multiplayer scene with several trenches on the ground. All the loaders, excavators, and cranes are working together. Fragment of bricks may drop from the tower crane. The player must avoid all potential hazards and pass this level without getting hurt.

Multiplayer scene with several trenches on the ground. All machinery (including the train) is working together. Players would be randomly assigned to any sites, and they have to work collaboratively to pass the training. For example, one could act as the operator, while the other stands in the blind zone.
The trainee would be spawned at point $A$ and is expected to move to point $B$ after reading through the instruction.

The player is required to move to point $\mathrm{C}$ securely, e.g., notify the operator of the excavator to stop working or move from A to $\mathrm{C}$ and maintain enough distance from the machinery.

The trainee would be spawned at point A and is expected to navigate to point $B$ securely, e.g., waiting for the truck to stop and notify the operator of the excavator to stop. Getting hurt or staying in the same place for over $1 \mathrm{~min}$ would be considered a failure.

Trainees would be spawned at point A and point $\mathrm{B}$. They can explore the whole scene at this level. Players will be removed after $5 \mathrm{~min}$, and they are expected to keep the other safe.

They would fail if they get injured or stay in the same place over $1 \mathrm{~min}$.

Trainees would be randomly spawned into the scene. They would act as a machinery operator and on-site worker. They would be removed after $5 \mathrm{~min}$ and $30 \mathrm{~s}$, and they are expected to keep the other safe. For failing, same conditions in level 03 applied.

The system was mainly controlled by a series of scripts based on C\# programming. All scripts worked collaboratively to ensure the commands were transferred correctly and appropriately from level 01 to level 04 , and they were communicating with each other every single frame during the system running period. Figure 6 reveals the planning 
algorithm behind this training program, in which the Scene Manager and Player Manager play significant roles in session control and player arrangement. Scene Manager and Return Manager would determine if trainees pass tests, for instance, if yes, transferring players to the next scene or if no, restarting the current scene. The Network Manager was in charge of multiplayer communication by using the application program interface. Sounds were attached to important objects such as machinery, trains, and vehicles, to restore reality to a greater extent. Once the player has passed the final level successfully, the End Game script would call the terminating methods and transfer the player to the "End Game" scene.

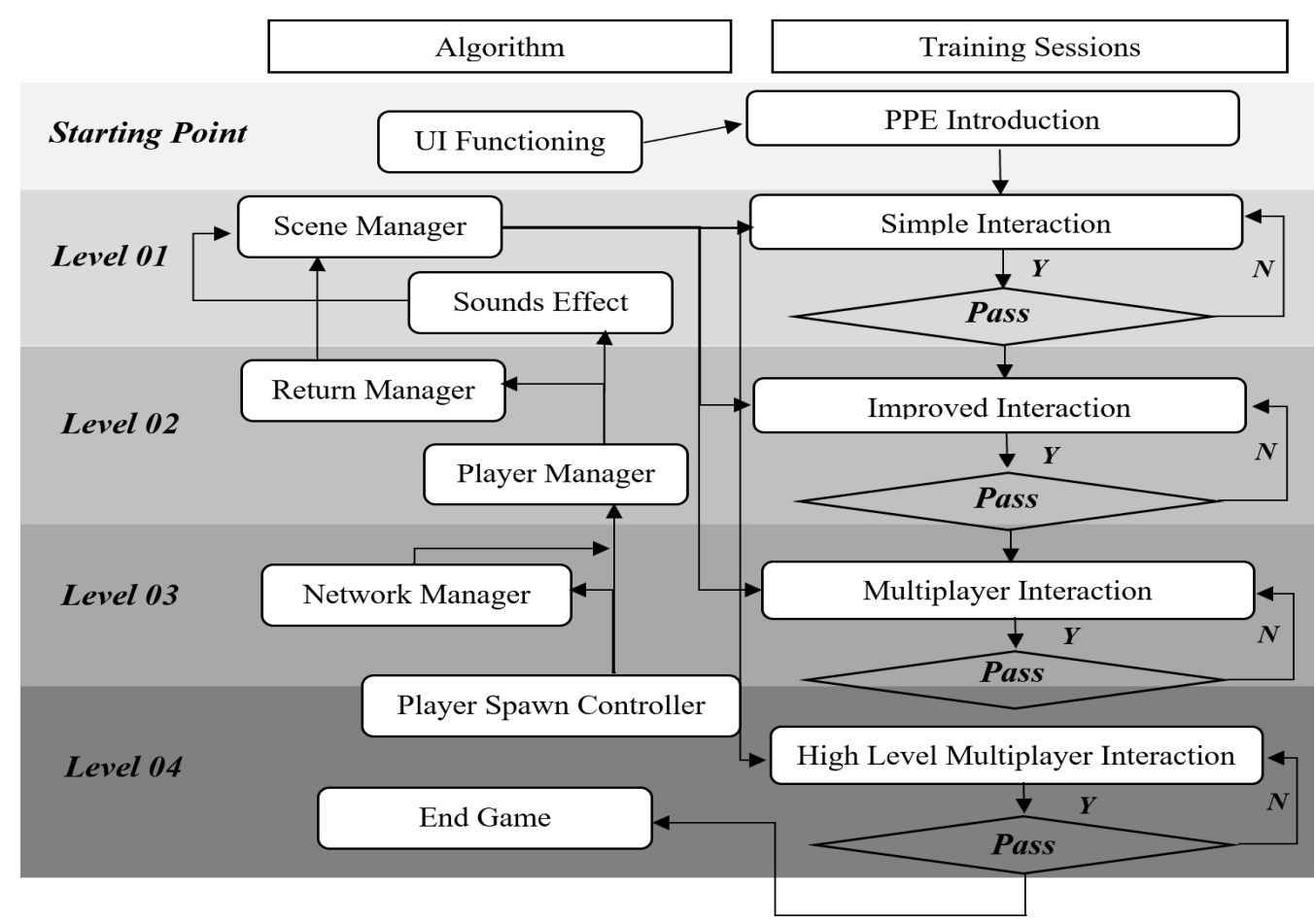

Figure 6. The controlling scripts associated with training sessions.

One prominent feature of the proposed platform is the introduction of the multiplayer platform. This is supported by the High-level Scripting API of Unity's networking function module [26]. For the purpose of the methodology description, the multiplayer service illustrated in Figure 7 enables two players to join in the scene simultaneously. A host (local client) is entailed to achieve this, and the observer will act as the host and create a virtual public room for trainees who have passed level 02 to join in. By doing this, trainees will be regarded as participants and have restricted access to the platform so that they cannot touch high-level game settings.

Trainees will be transferred to another UI after they passed level 02 . They will see the list of the next training sessions in this UI, and they could have access to these scenes by single-clicking on the controller. These sessions were created by the local client (the observer) to achieve the multiplayer connection. Two trainees will be linked to the local client with the assistance of Unity's network manager, and the observer will be able to observe the performance of trainees. 


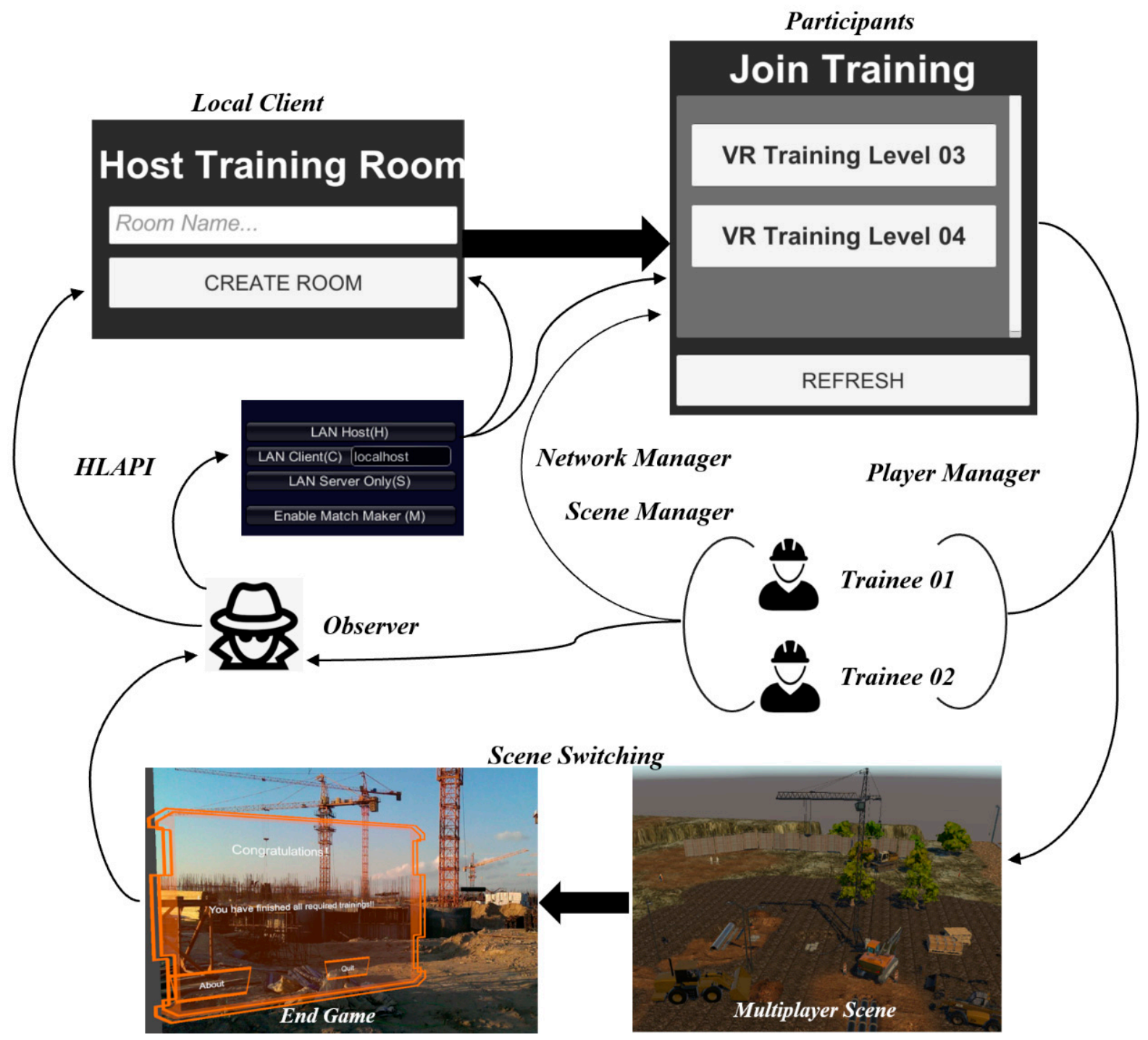

Figure 7. An illustration of the multiplayer system: a two-play case.

\subsection{Survey Design}

In terms of the validation of this proposed training solution, a pilot study was conducted in a railway station (Pakenham Station, Melbourne, VIC) that was under construction (Figure 8). Several machinery types were working together for both site rebuild and level crossing removal, and a survey plan was made for workers involved in this project with the permission of the construction company. To guarantee the efficiency and accuracy of obtaining valuable feedback from subjects, the questionnaire survey was designed. Several studies $[27,28]$ have proven the efficiency of a specifically designed questionnaire survey with regard to saved time and explicit purpose. The evaluation survey for this study aims to validate the usefulness of the multiplayer VR training system through a comparison with traditional training methods by gathering participants' feedback regarding their perception and reaction. Inexperienced workers were the preference for this evaluation survey, and a demographic questionnaire was prepared to screen out people who have over two years of experience in construction areas, since workers' safety recognition ability has a correlation with work experience [5,7]. Eventually ten workers (a Mean of 27.7 years, and a Standard Deviation of 2.2 years), including two new employees, were selected as the eligible members of the VR training tests. They all expressed a willingness to participate in such studies. A Simulator Discomfort Questionnaire (SSQ) [29] was prepared for this simulation study to reveal if any participant suffered any 3D-motion sickness. 

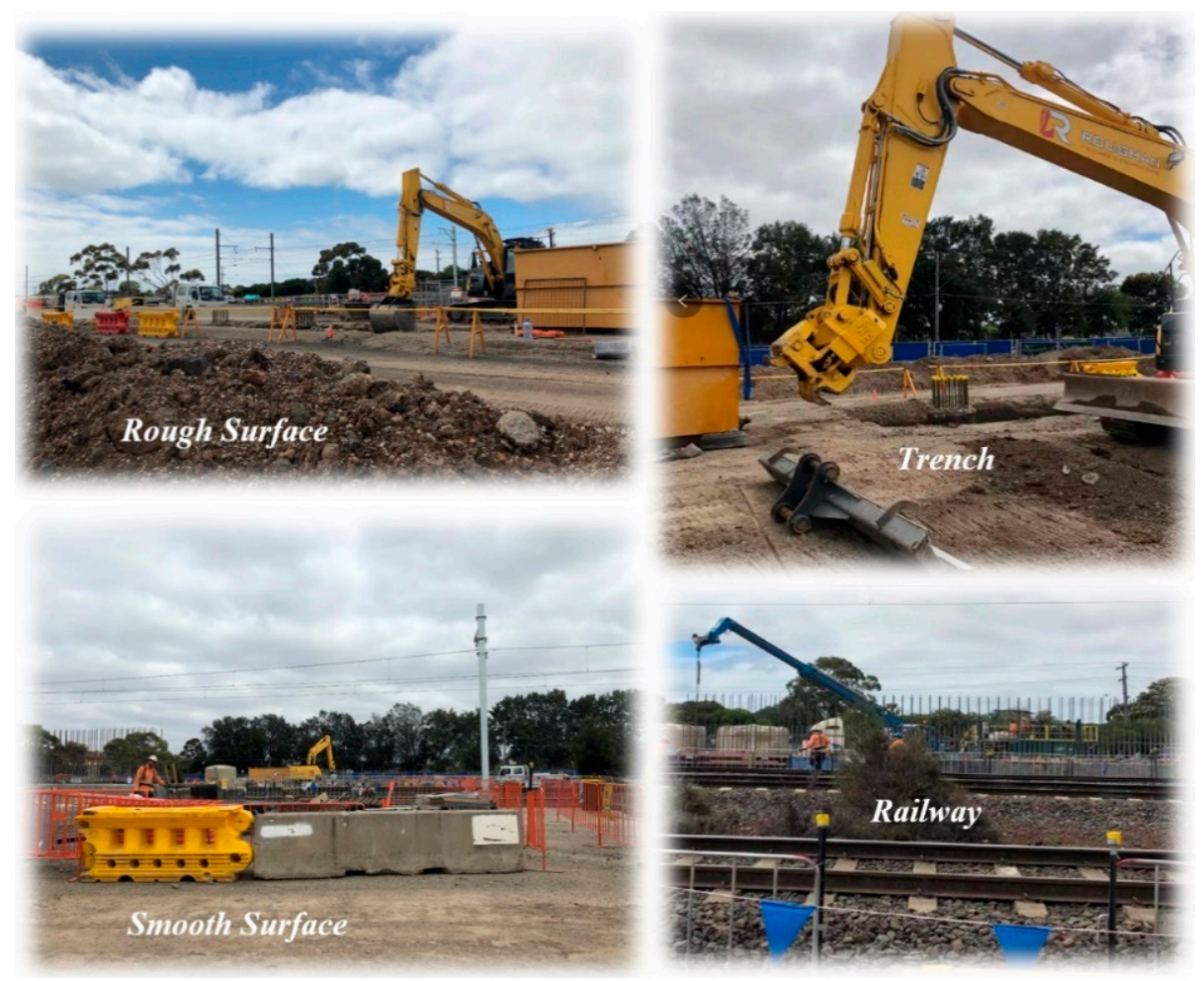

Figure 8. Features in the target construction site (photos taken by the authors).

The participants were told they would attend a safety training delivered by a VR headset for around $20 \mathrm{~min}$. The evaluation survey was based on a compared-measures design, which means a participant was required to be trained through different methods (in this case, the traditional video instruction, and the VR training solution). Participants were also instructed to navigate themselves using the controller (showed in Figure 5). Each participant's session consisted of two parts: traditional training (part I) and VR training (part II). The training took place in a media room at the construction site. Participants were also notified before the start of the VR training that they might experience some discomfort during the training, namely dizziness, sweating, or headache, but they were allowed to ask observers to terminate the training if they felt unwell, even to a minor degree.

The entire survey time was around $30 \mathrm{~min}$ for each person $(15 \mathrm{~min}$ for Part I and $15 \mathrm{~min}$ for Part II), and the data were collected by questionnaires and observations. Questionnaires were anonymized using participant IDs. The participants' performance in the VR environment was recorded with their knowledge, but the footage of the actual participants was not captured. The Van der Laan Acceptance Scale [30] was used to assess how the participants regarded the VR training platform eventually, and future scopes of VR in research could be identified based on the results. The content of the questionnaires is shown in Table 2. 
Table 2. Questionnaire content.

\begin{tabular}{|c|c|c|c|}
\hline Survey Topic & Application & Questions & Responses \\
\hline \multirow{4}{*}{ Demographics } & \multirow{4}{*}{ Given before the training } & Gender; age; working experience (years) & In numbers \\
\hline & & Average working time per day (hours) & $"<6 "-{ }^{\prime \prime}>8 "$ \\
\hline & & Injured times (can be specified) & “0”-“>5” \\
\hline & & Previous experience with VR & $“ 0 "-“>10 ”$ \\
\hline Simulator discomfort & $\begin{array}{l}\text { Given before and after } \\
\text { the training }\end{array}$ & $\begin{array}{c}\text { Evaluation subscales were used to assess } \\
\text { general discomforts such as fatigue, } \\
\text { headache, eyestrain, sweating, nausea, } \\
\text { dizzy, etc. }\end{array}$ & Slight, moderate, and severe. \\
\hline $\begin{array}{l}\text { Perception of the VR } \\
\text { training platform }\end{array}$ & Given after the training & $\begin{array}{c}\text { Whether the training sessions are more } \\
\text { impressive; whether nervousness was } \\
\text { experienced; whether it was easy to move } \\
\text { around; whether it is easier to getting } \\
\text { hurts in VR environment; whether lost; } \\
\text { whether the VR system provided good } \\
\text { visualization }\end{array}$ & $\begin{array}{l}\text { The 5-point Likert scale } \\
\text { ("strongly disagree 1" to } \\
\text { "strong agree } 5 \text { "). }\end{array}$ \\
\hline Simulating realism & Given after the training & $\begin{array}{l}\text { Whether the decent visualization was } \\
\text { provided; whether it helped improve } \\
\text { safety awareness; simulator realism. }\end{array}$ & $\begin{array}{l}\text { "strongly disagree } 1 \text { " to } \\
\text { "strong agree 5"; “very poor } \\
(0) \text { " to "excellent (5)". }\end{array}$ \\
\hline
\end{tabular}

\section{Training Experiment Results}

The results are delivered based on the performance of participants and their responses to the questionnaire.

\subsection{Training Performance}

Data from the demographic questionnaire illustrated that all participants had at least one year of working experience with 6 to $8 \mathrm{~h}$ of work per day. They all experienced getting injured during the construction work. Table 3 summarizes the participants' information.

Table 3. Demographic makeup of participants.

\begin{tabular}{cccc}
\hline Characteristic & Percentage (\%) & Characteristic & Percentage (\%) \\
\hline Gender & \multicolumn{3}{c}{ Average working time per day $(h)$} \\
Male & 100 & Less than 6 & 0 \\
Female & 0 & $6-8$ & 80 \\
Age & 20 & More than 8 & 20 \\
$18-25$ & 80 & Injured times & \\
$26-40$ & 70 & $0-1$ & 20 \\
Working Experience (years) & 30 & $1-2$ & 60 \\
$0-1$ & 0 & Experience with VR & 30 \\
$1-2$ & & 0 & 10 \\
More than 2 & & More than 3 & \\
& &
\end{tabular}

The observed performance showed that all participants (100\%) appreciated PPE's significance and quickly passed levels 1 and 2 . However, it was evident that participants tended to perceive the training session more like a game scene when it came to level 3 and 4 , and $60 \%$ of them were getting hurt during the world exploration or interaction with other mock objects or trainees. Consequently, the average time they spent during level 03 and 04 were longer than the time for level 01 and 02 (10 min vs. $4 \mathrm{~min})$. The manifest failures include (1) getting hit by falling fragments from the crane; (2) dropping into the trench; (3) moving into the machinery's blind zone; (4) getting hit by a moving vehicle, and (5) being tripped by other objects. Figure 9 displays the mentioned failures from the visual animation records. On average, participants restarted level 03 and 04 more than twice. 


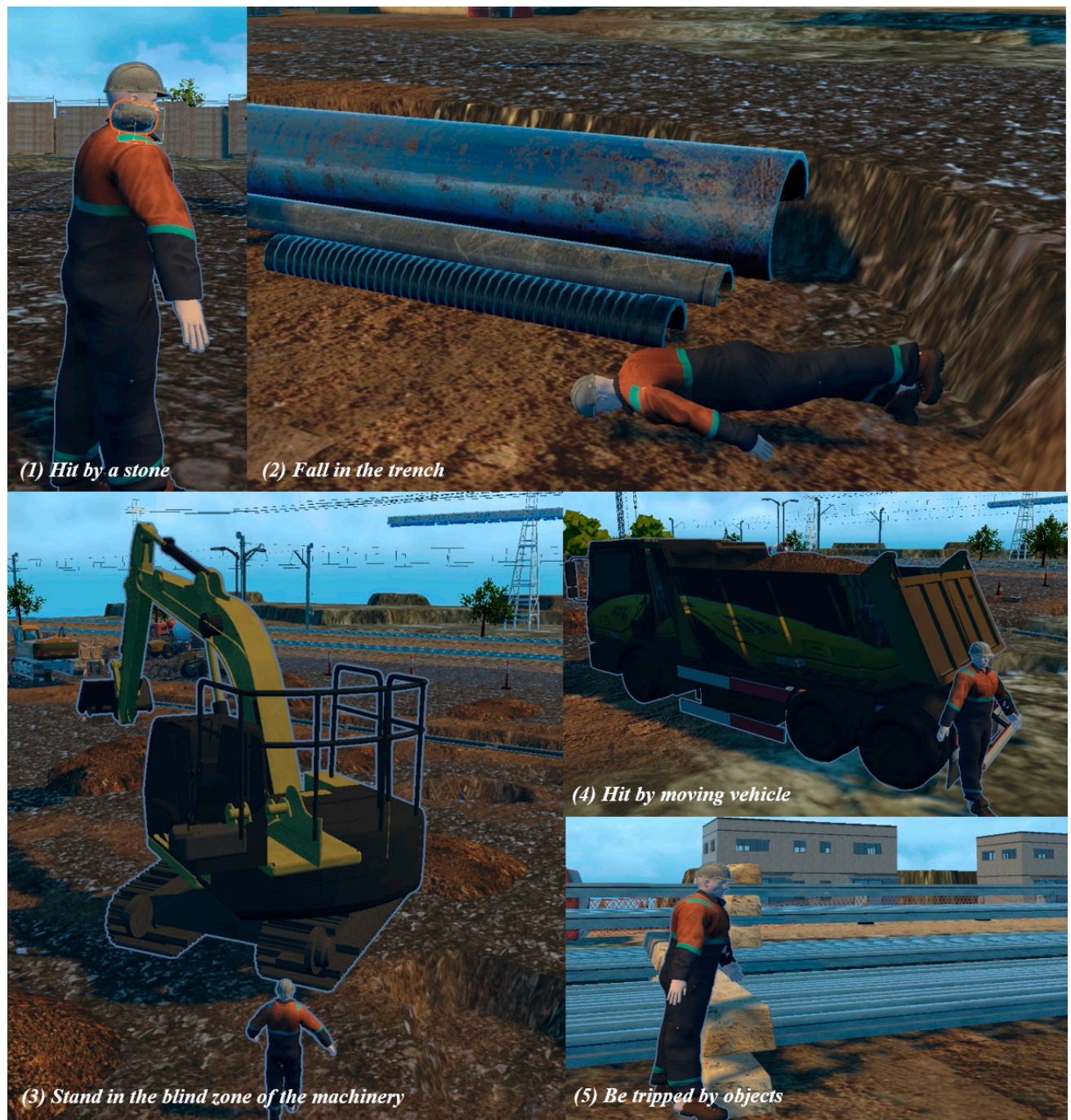

Figure 9. The observed failures.

Participants were randomly grouped in pairs and spawned to the scene in terms of the multiplayer scenarios (level 03 \& 04). One would act as an operator of the machinery, and another would stand on the ground as a fieldworker; trainees would swap their roles to the next level. It was intriguing that, in general, machine operators performed worse. The reason is that they could be distracted by the environment (e.g., the background view), the machine itself (e.g., the cabin design and functions), and be as careless as if it were a game, all of which reflected real-world issues onsite. As a result, the operators misconducted the machines, hitting people and colliding with other objects. The relative positions of participants in different scenarios are illustrated in Figure 10, and the potential hazards involved (1) a trainee stands too close to a working loader, and the loader is colliding with a cementing truck; (2) the machinery operator was too concentrated on moving the container and ignored a fieldworker who was working at a very close distance; (3) The shovel car operator failed to detect a fieldworker to his right front, and a flying stone accidentally hit this fieldworker. 


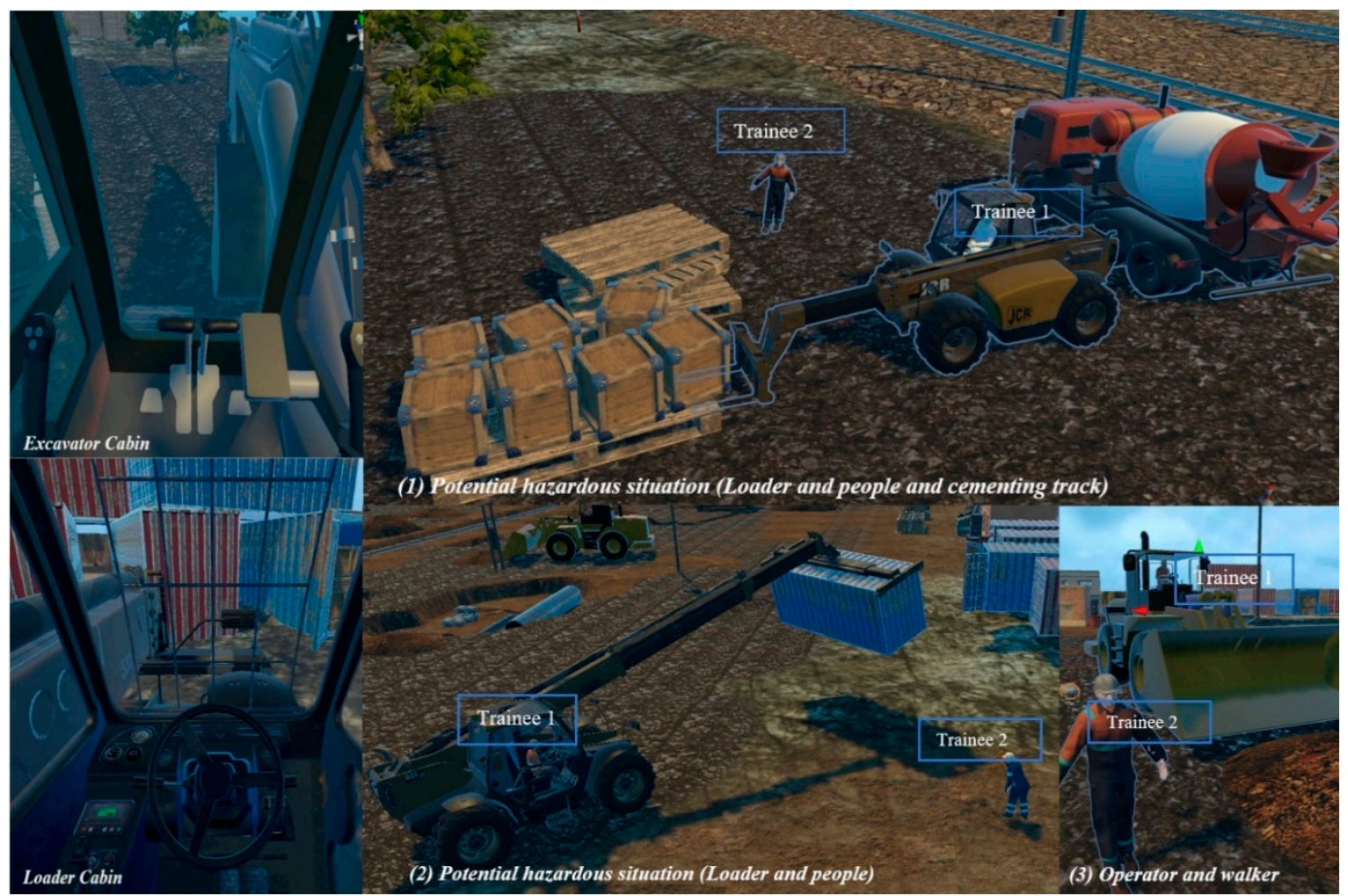

Figure 10. Hazardous situations in multiplayer scenes.

Participants tended to make more mistakes on their first or second attempts, mostly collisions. Most of them (8 out of 10) acclimated themselves quickly and passed the training sessions within three attempts. Two participants somehow moved away from the targeted area when doing level 03, but their effective attempts were within three attempts, as well. During the VR training time, all participants exhibited excitation when they entered the introduction scene. After they passed level 02 , such excitation remained moderately and was aroused at the multiplayer scene and as they passed the tasks. They appeared to be cheerful and enjoy themselves after passing; for example, shouting, waving, and jumping were observed. Interestingly, several participants (6 out of 10) were observed having body movement while they were performing certain maneuvers, which they were supposed to control through a controller. This is a good sign that the trainees felt the scenes. Only two participants were observed making repetitive mistakes, namely being hit by falling stones twice in level 04, while others performed well in preventing themselves from this particular hazard. Eighty percent of participants were able to avoid the tricky risks (stone falling randomly from the crane) after their first failure, indicating an increasing trend of safety recognition.

No participant felt uncomfortable or asked for any suspension or termination during the survey period. The trainees also reported that their performance was not influenced by any discomfort. This was a good result, as according to the previous study [6], some external factors such as room temperature, physical conditions, emotional fluctuations, and time of day can cause 3D motion sickness to different extents, and minor discomfort levels after the VR training was expected from us. Perhaps it helped that the trainees were advised to drink a cup of water before attending the VR training program.

\subsection{Feedback from Participants}

On the 5-point Likert scale (from "strongly disagree 1" to "strong agree 5"), the users' perception regarding VR training platform was therefore assessed. Reliability analysis was used to evaluate participant consistency in different training solutions as well. Notably, over $90 \%$ of participants stated that the VR training sessions are more impressive, and only 
a few people felt nervous and hard to control (1 out of 10). However, participants tended to get hurt or even lost during their first attempts, especially in levels 03 and 04 .

Based on the scale feedback, we estimated a Cornbach's alpha $\left(\rho_{T}\right)$ which represents the internal consistency of participants' perception regarding the VR training sessions. If the value of $\rho_{T}$ is between 0.60 and 0.70 in an exploratory experiment, the results could be regarded as reliable [31]. In this study, the VR training platform was perceived as reliable as the acceptable consistency was found with $\rho_{T}=0.64$ (Table 4), indicating that the proposed training solution is satisfactory and reliable.

Table 4. Participant feedback regarding VR training session.

\begin{tabular}{|c|c|c|c|c|c|c|}
\hline \multirow[b]{2}{*}{ Perception of Training Sessions } & \multicolumn{3}{|c|}{ Traditional } & \multicolumn{3}{|c|}{ Virtual Reality } \\
\hline & $\mathbf{M}^{1}$ & $\mathrm{SD}^{2}$ & $\begin{array}{l}\text { Cronbach's } \\
\text { Alpha }\left(\rho_{T}\right)\end{array}$ & $\mathbf{M}^{1}$ & $\mathrm{SD}^{2}$ & $\begin{array}{l}\text { Cronbach's } \\
\text { Alpha }\left(\rho_{T}\right)\end{array}$ \\
\hline Whether sessions are impressive & 1.50 & 0.50 & & 4.50 & 0.71 & \\
\hline Whether felt nervous & 1.00 & 0.00 & & 2.00 & 1.12 & \\
\hline Whether it was easy to move & 4.13 & 0.59 & 0.60 & 3.63 & 1.41 & 0.64 \\
\hline Whether got hurts & 1.00 & 0.00 & & 3.63 & 1.41 & \\
\hline Whether lost & 1.13 & 0.33 & & 3.75 & 1.30 & \\
\hline
\end{tabular}

$\mathrm{M}^{1}=$ Mean, $\mathrm{SD}^{2}=$ Standard deviation.

As for the realism simulation assessment, the feedback from participants revealed that the realism of the VR simulating was acceptable, with $\rho_{T}=0.65$ (Table 5). The results demonstrate that participants appreciated the immersive environment provided by VR and believe that this can help to improve safety awareness as a decent training tool.

Table 5. Participant feedback regarding VR simulating.

\begin{tabular}{clcc}
\hline VR Simulating Realism & $\mathbf{M}^{\mathbf{1}}$ & $\mathbf{S D}^{\mathbf{2}}$ & Cronbach's Alpha $\left(\rho_{T}\right)$ \\
\hline Good Visualization & 3.90 & 0.83 & \\
Difficult to Operate & 2.00 & 1.18 & \\
Improve Safety Awareness & 4.00 & 1.00 & 0.65 \\
Good Training Tool & 3.40 & 1.02 & \\
More Impressive & 4.10 & 0.83 & \\
\hline
\end{tabular}

$\mathrm{M}^{1}=$ Mean, $\mathrm{SD}^{2}=$ Standard deviation.

\section{Discussion}

\subsection{Participant Perception}

A critical objective for the proposed platform to achieve is to help trainees realize and avoid safety mistakes in different construction site scenarios. The design of the platform thus should reflect the relationship between the complexity of the scenes and the mistake features by the workers. There was a clear observed correlation between the scene's complexity and the trainee error rate. To quantitatively analyze this relationship, the training levels are converted into a hazard identification index (HII) [32]. The HII values the potential hazards in a specific scenario and is usually calculated for each trainee using the equation:

$$
H I I_{j}=\frac{H_{i}}{H_{\text {total }}}
$$

where $H_{i}$ represents the number of hazards that could be identified at a specific site (i), and $H_{\text {total }}$ is the number of hazards around the trainee. The $H_{i}$ in this study was presupposed in each training level (e.g., 5 potential hazards in total in level 01, and 20 potential hazards in total in level 04 ), and had different impacts on trainee perception. $H I I_{j}$ represents the hazards each trainee faced in each frame corresponding to that site.

The participants' perceptions regarding different training levels are demonstrated in Figure 11. Participants during the training period tended to explore the VR world first. 
They passed level 01 effortlessly without identifying all the potential hazards. Numerically, the low standard deviation indicates that the number of perceived hazards tended to be close to the mean. The same situation happened in level 02. Participants could acclimate themselves quickly and found out the easiest way to avoid risks and pass the level. Most participants (90\%) performed well and identified all the presupposed hazards in this scene. However, when failures started to emerge in multiplayer modes, participants ability to identify potential hazards were negatively affected. They failed mainly due to ignoring some unpredictable accidents such as being hit by a stone falling from the crane or a rock that was blown away by machinery. As a result, participants were only able to identify half of the presupposed hazards. An improved trend of safety recognition was seen during the training session. Participants identified more potential hazards in level 04 compared to 03 , though level 04 is more complicated. A relatively low standard deviation indicates that all participants identified more risks in level 04.

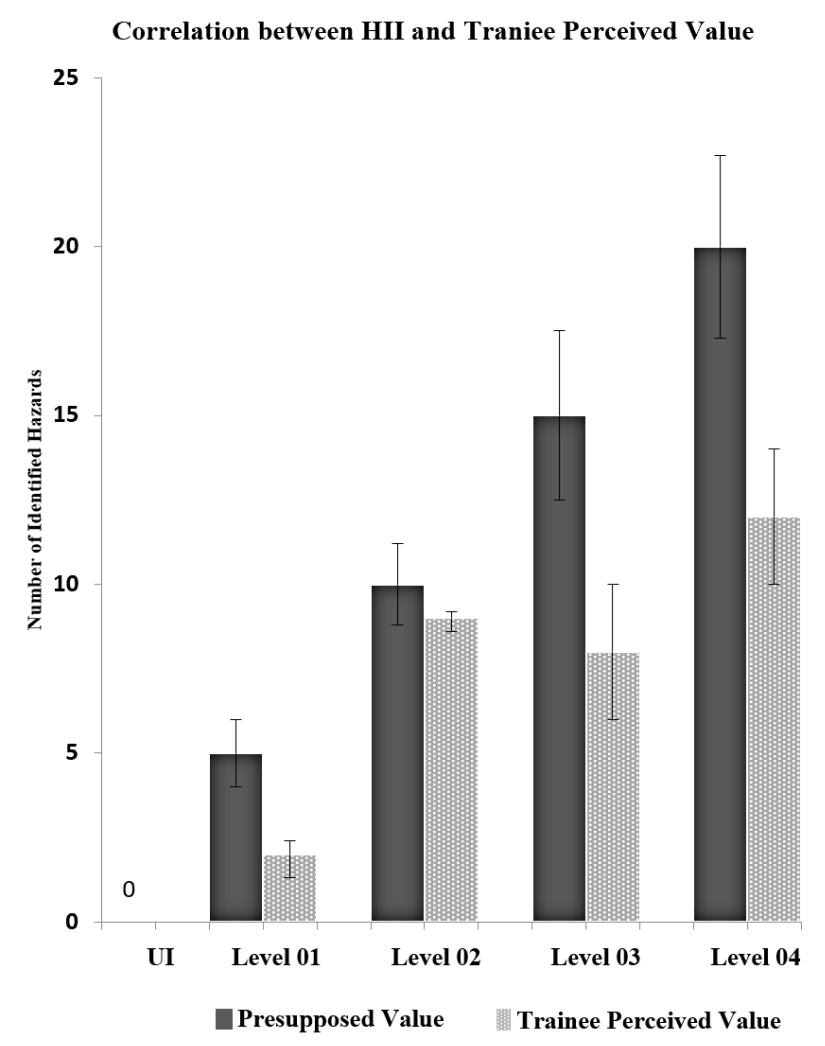

Figure 11. Correlation between Hazard Identification Index and Trainee Perceived Value.

Statistically, the moving of machinery such as excavators and shovel cars significantly impacted the route selection $(p=0.003)$. The number of running machinery and the surface smoothness was also found to significantly affect participants' safety awareness, with $p<0.001$. Besides, a significant interaction was found between sound effects and trainee decision making $(p<0.001)$, which was visualized as a sudden move to an open space in the VR scene. Trainees' error rate was found to have the same trend with the increased hazards, indicating that workers can still neglect some key points when facing a complicated construction area, even though they have one-year working experience. While no significant interaction was identified in single and multiplayer scenes with the player's safety recognition ( $p=0.1$ ), over $60 \%$ of participants spent more time finishing multiplayer scenes. The moving machinery mainly influenced participants on the construction sites, and trainee performance showed that more than $70 \%$ of participants pointed out all the potential risks around the running machinery and successfully protected themselves. 


\subsection{Participant Performance Regarding 3D Motion Sickness}

In terms of 3D motion sickness, no participant has suffered even a moderate sideeffect throughout the whole training session, and only 1 of 10 sustained a minor headache. The results of SSQ are shown below (Figure 12).

\section{Discomfort levels before and after training}

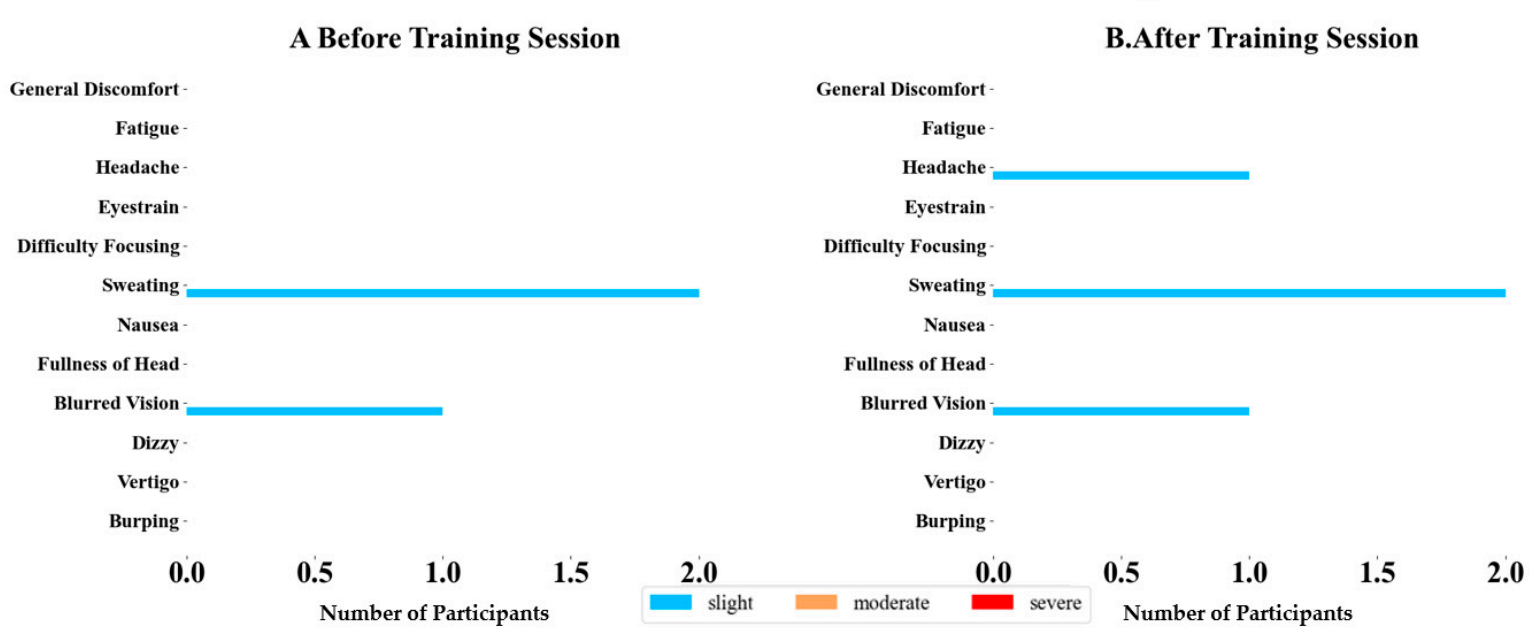

Figure 12. Comparison between discomfort levels.

\subsection{Implications}

It is worth noting that the results of this study are consistent with the findings from some research [9,12-14], concluding that VR is a useful educational tool which can be a decent substitute for conventional training methods due to its potential for providing an immersive experience associated with extensible and flexible interactions. This project amplified the existing immersive virtual reality technology and proposed a multiplayer platform to improve the interaction between participants, thereby providing a clue for the development of safety training and accident avoidance for future works. This VR training solution has been proven to impress trainees to a great extent by allowing them to visualize every hazardous situation without them really getting hurt. The conception of this simulated open-world training solution is also applicable to some other simulating studies for behavioral analysis.

\subsection{Limitations}

Although the proposed multilevel training platform involves newly discovered ideas and the latest VR technologies, some limitations still exist. Firstly, according to participants ${ }^{\prime}$ feedback, levels 03 and 04 are relatively difficult to pass due to overly abundant rendering and animating, resulting in making trainees confused and distracted. Further training design should emphasize critical points such as hazards presented in each 360-degree view, a single player's specific range. The complicated rendering process also presents challenges for hardware to calculate the environment in every frame; consequently, the resolution is negatively affected after the system has been operating for a long time. Besides, state-ofthe-art modelling skills are entailed to guarantee a high-immersion virtual environment, thereby contributing to a better-validated outcome $[14,17,33]$. Secondly, the VR training session in this study was delivered using a wireless VR goggle associated with one controller; however the platform was still a relatively fixed one and participants were not allowed to move around in the real world, which reduced the realism of the immersive experience. A 360-degree walking pad could be considered to be connected with the player control to allow the actual movement for future development. Lastly, the platform validation, albeit participated by real construction project workers, was carried out on 
a relatively small sample. A larger sample size would likely confirm the performance findings, system evaluation, and the test of 3D motion sickness analysis, and potentially lead to more insights.

\section{Conclusions}

This study has demonstrated the feasibility of a multiplayer VR training solution for construction areas. The logical interactions delivered by such an immersive environment were perceived as impressive and attractive, and the classification based on the hierarchy of complexity provides a clear direction for application design in the future. The conception of setting different levels to familiarize players with the virtual world has proven effective. The advancement in simulation techniques has provided an enormous convenience for educational purposes and leads to innovation and creativity standing on the extensible and scalable properties. Training through experience enables new entrants to memorize critical points with less effort securely, and the idea of virtual training should be amplified to produce more efficient methods for saving educational costs and incidental costs.

In fact, the real world is more than complicated, and thousands of unpredictable, unstable, and unreliable variables are working simultaneously to make life rich and colorful. Thus, the main objective of future development should emphasize the more detailed recreating degree to update and diversify the scenes, thereby generating more opportunities to substitute the conventional training methods and on-site training programs entirely. Besides, platform development and improvement are always possible from a programming point of view. The judicious utilization of $\mathrm{C \#}$ programming would allow us to explore more simulating applications.

Lastly, according to the Sustainable Development Goals (SDGs), safe and secure working environments for all workers are promoted, and a workplace with improved security is intimately bound with the integrated SDGs implementation [34,35]. It is evident that an effective training solution incorporating emerging technologies can improve workers' safety awareness and reduce the probability of injury, thereby contributing to a safer and more reliable working environment. Fewer workers getting hurt during construction projects can improve working efficiency and facilitate engagement, resulting in more sustainable workplaces. The escalation of digitalized innovative approaches and practices is crucial for sustainable construction [36]. As a state-of-the-art technology, virtual reality provides a scalable and extensible platform that sheds light on the development of the future of the construction industries.

Author Contributions: Conceptualization, Z.X. and N.Z.; methodology, Z.X.; software, Z.X.; validation, Z.X. and N.Z.; formal analysis, Z.X.; investigation, Z.X. and N.Z.; resources, Z.X.; data curation, Z.X.; writing—original draft preparation, Z.X.; writing—review and editing, Z.X. and N.Z.; visualization, Z.X.; supervision, N.Z. All authors have read and agreed to the published version of the manuscript.

Funding: This research received no external funding.

Institutional Review Board Statement: This study was conducted according to the Global Mandatory Requirements guidelines for safety and environment provided by John Holland Pty Ltd., Melbourne, Australia, and approved by John Holland (03/2019).

Informed Consent Statement: Informed consent was obtained from all subjects involved in the study.

Data Availability Statement: Part of the data presented in this study is available on request from the corresponding author. The data are not publicly available due to the size and license permission of Unity project files.

Acknowledgments: This project was supported by John Holland Pty Ltd., Melbourne, Australia. Special thanks to Poojith Cherukattu and Cynthia RajaSharmishta for coding and modelling supports. The project would never run smoothly without their creative ideas, exclusive efforts, and selfless dedication.

Conflicts of Interest: The authors declare no conflict of interest. 


\section{References}

1. Safe Work Australia. WHS Statistics Australia. Available online: https://www.safeworkaustralia.gov.au/taxonomy/term/17 (accessed on 5 November 2020).

2. Safe Work Australia. Key Work Health and Safety Statistics. Available online: https://www.safeworkaustralia.gov.au/doc/keywork-health-and-safety-statistics-australia-2020 (accessed on 5 November 2020).

3. Garrett, J.W.; Teizer, J. Human factors analysis classification system relating to human error awareness taxonomy in construction safety. J. Constr. Eng. Manag. 2009, 135, 754-763. [CrossRef]

4. Burke, M.J.; Sarpy, S.A.; Smith-Crowe, K.; Chan-Serafin, S.; Salvador, R.O.; Islam, G. Relative effectiveness of worker safety and health training methods. Am. J. Public Health 2006, 96, 315-324. [CrossRef] [PubMed]

5. Goetsch, D. Construction Safety E Health, 2nd ed.; Pearson: Boston, MA, USA, 2013.

6. Bhoir, S.; Esmaeili, B. State-of-the-art review of virtual reality environment applications in construction safety. In Proceedings of the AEI 2015, Milwaukee, WI, USA, 24-27 March 2015.

7. Perlman, A.; Sacks, R.; Barak, R. Hazard recognition and risk perception in construction. Saf. Sci. 2014, 64, 22-31. [CrossRef]

8. Moore, H.F.; Eiris, R.; Gheisari, M.; Esmaeili, B. Hazard Identification Training Using 360-Degree Panorama vs. Virtual Reality Techniques: A Pilot Study. In Proceedings of the ASCE International Conference on Computing in Civil Engineering 2019, Atlanta, GA, USA, 17-19 June 2019.

9. Zuluaga, C.M.; Namian, M.; Albert, A. Impact of training methods on hazard recognition and risk perception in construction. In Proceedings of the Construction Research Congress, San Juan, Puerto Rico, 31 May-2 June 2016; pp. $2861-2871$.

10. Kuligowski, E.D.; Walpole, E.H.; Lovreglio, R.; McCaffrey, S. Modelling evacuation decision-making in the 2016 Chimney Tops 2 fire in Gatlinburg, TN. Int. J. Wildland Fire 2020, 29, 1120-1132. [CrossRef]

11. Lovreglio, R.; Duan, X.; Rahouti, A.; Phipps, R.; Nilsson, D. Comparing the effectiveness of fire extinguisher virtual reality and video training. Virtual Real. 2020. [CrossRef]

12. Dickinson, J.K.; Woodard, P.; Canas, R.; Ahamed, S.; Lockston, D. Game-based trench safety education: Development and lessons learned. J. Inf. Technol. Constr. 2011, 16, 119-134.

13. Guo, H.; Li, H.; Chan, G.; Skitmore, M. Using game technologies to improve the safety of construction plant operations. Accid. Anal. Prev. 2012, 48, 204-213. [CrossRef]

14. Sacks, R.; Perlman, A.; Barak, R. Construction safety training using immersive virtual reality. Constr. Manag. Econ. 2013, 31, 1005-1017. [CrossRef]

15. Pedro, A.; Le, Q.T.; Park, C.S. Framework for integrating safety into construction methods education through interactive virtual reality. J. Prof. Issues Eng. Educ. Pract. 2016, 142, 04015011. [CrossRef]

16. Feng, Z.; González, V.A.; Amor, R.; Spearpoint, M.; Thomas, J.; Sacks, R.; Lovreglio, R.; Cabrera-Guerrero, G. An immersive virtual reality serious game to enhance earthquake behavioral responses and post-earthquake evacuation preparedness in buildings. Adv. Eng. Inform. 2020, 45, 101118. [CrossRef]

17. Xu, Z.; Zou, X.; Oh, T.; Vu, H.L. Studying freeway merging conflicts using virtual reality technology. J. Saf. Res. 2020, in press. [CrossRef]

18. Bric, J.D.; Lumbard, D.C.; Frelich, M.J.; Gould, J.C. Current state of virtual reality simulation in robotic surgery training: A review. Surg. Endosc. 2016, 30, 2169-2178. [CrossRef] [PubMed]

19. Thomsen, A.S.S.; Bach-Holm, D.; Kjærbo, H.; Højgaard-Olsen, K.; Subhi, Y.; Saleh, G.M.; Park, Y.S.; la Cour, M.; Konge, L. Operating room performance improves after proficiency-based virtual reality cataract surgery training. Ophthalmology 2017, 124, 524-531. [CrossRef] [PubMed]

20. Berg, L.P.; Vance, J.M. Industry use of virtual reality in product design and manufacturing: A survey. Virtual Real. 2017, $21,1-17$. [CrossRef]

21. Amaguaña, F.; Collaguazo, B.; Tituaña, J.; Aguilar, W.G. Simulation system based on augmented reality for optimization of training tactics on military operations. In Augmented Reality, Virtual Reality and Computer Graphics; Springer: Cham, Switzerland, 2018; pp. 394-403.

22. Hamid, A.R.A.; Yusof, W.Z.W.; Singh, B.S.B.J. Hazards at construction sites. In Proceedings of the 5th Asia-Pacific Structural Engineering and Construction Conference (APSEC 2003), Johor Bahru, Malaysia, 26-28 August 2003.

23. Oculus.com. 2018. Oculus Quest: Our Most Advanced All-In-One VR Headset I Oculus. Available online: https: / / www.oculus. com/quest (accessed on 5 December 2018).

24. Johnholland.com.au. Health \& Safety: John Holland. Available online: https://www.johnholland.com.au/our-approach/healthsafety / (accessed on 5 November 2018).

25. Buyuksalih, I.; Bayburt, S.; Buyuksalih, G.; Baskaraca, A.P.; Karim, H.; Rahman, A.A. 3D Modelling and Visualization Based on the Unity Game Engine-Advantages and Challenges. ISPRS Ann. Photogramm. Remote. Sens. Spat. Inf. Sci. 2017, 4, 161. [CrossRef]

26. Docs.unity3d.com. Unity—Manual: Multiplayer Overview. Available online: https://docs.unity3d.com/Manual/UNetOverview. html (accessed on 12 December 2018).

27. Lunkes, R.J.; Rosa, F.S.; Monteiro, J.J.; Bortoluzzi, D.A. Interactions among Environmental Training, Environmental Strategic Planning and Personnel Controls in Radical Environmental Innovation. Sustainability 2020, 12, 8748. [CrossRef] 
28. Olmos-Gómez, M.C.; Luque-Suárez, M.; Mohamed-Mohamed, S.; Cuevas-Rincón, J.M. Validation of the Smart City as a Sustainable Development Knowledge Tool: The Challenge of Using Technologies in Education during COVID-19. Sustainability 2020, 12, 8384. [CrossRef]

29. Kennedy, R.S.; Lane, N.E.; Berbaum, K.S.; Lilienthal, M.G. Simulator sickness questionnaire: An enhanced method for quantifying simulator sickness. Int. J. Aviat. Psychol. 1993, 3, 203-220. [CrossRef]

30. Van Der Laan, J.D.; Heino, A.; De Waard, D. A simple procedure for the assessment of acceptance of advanced transport telematics. Transp. Res. Part C Emerg. Technol. 1997, 5, 1-10. [CrossRef]

31. Nunally, J.; Bernstein, L. Psychometric Theory; MacGrow-Hill Higher: New York, NY, USA, 1994.

32. Carter, G.; Smith, S.D. Safety hazard identification on construction projects. J. Constr. Eng. Manag. 2006, 132, 197-205. [CrossRef]

33. Stephenson, R.S.; Atkinson, A.; Kottas, P.; Perde, F.; Jafarzadeh, F.; Bateman, M.; Iaizzo, P.A.; Zhao, J.; Zhang, H.; Anderson, R.H.; et al. High resolution 3-dimensional imaging of the human cardiac conduction system from microanatomy to mathematical modeling. Sci. Rep. 2017, 7, 7188. [CrossRef] [PubMed]

34. Breuer, A.; Janetschek, H.; Malerba, D. Translating Sustainable Development Goal (SDG) Interdependencies into Policy Advice. Sustainability 2019, 11, 2092. [CrossRef]

35. Hegre, H.; Petrova, K.; von Uexkull, N. Synergies and Trade-Offs in Reaching the Sustainable Development Goals. Sustainability 2020, 12, 8729. [CrossRef]

36. Fokaides, P.A.; Apanaviciene, R.; Černeckiene, J.; Jurelionis, A.; Klumbyte, E.; Kriauciunaite-Neklejonoviene, V.; Pupeikis, D.; Rekus, D.; Sadauskiene, J.; Seduikyte, L.; et al. Research Challenges and Advancements in the field of Sustainable Energy Technologies in the Built Environment. Sustainability 2020, 12, 8417. [CrossRef] 